Glioblastoma in patients with colorectal cancer has a more favorable prognosis and longer survival than usual. Familial clustering occurs in families with APC, $40 \%$ of families having two members with brain tumors. Tumor DNA testing for the incidence of mutations in APC genes in sporadic cases of medulloblastoma would be of interest (Groden J.

Colon-cancer genes and brain tumors. N Engl I Med March 30;332:884-5).

\title{
OPTIC PATHWAY TUMORS AND PRECOCIOUS PUBERTY
}

The prevalence of precocious puberty and its relationship to optic pathway tumors (OPTs) have been examined in 219 children with neurofibromatosis 1 (NF-1) seen between Jan 1985 and April 1993 at Children's Memorial Hospital, Chicago. Of seven (3\%) with precocious puberty, all had OPTs which involved the optic chiasm and all had abnormal luteinizing hormone-releasing hormone (LH-RH) stimulation tests. They represented 39\% of children with NF-1 and chiasmal tumors. Seventy-six percent of OPTs were detected by screening with neuroimaging rather than by clinical symptoms. Biochemical evidence of premature hypothalamic-pituitary-gonadal axis activation may be demonstrated by LH assay, without provocative testing, before overt signs of puberty appear. (Habiby R, Silverman B, Listernick R, Charrow J. Precocious puberty in children with neurofibromatosis 1. L Pediatr March 1995;126:364-7). (Reprints: Joel Charrow MD, Division of Genetics, Children's Memorial Hospital, 2300 Children's Plaza, Chicago, IL 60614).

COMMENT. Precocious puberty associated with neoplastic invasion of the hypothalamus has been reported with gliomas, hamartomas, infundibulomas, and supracellar cysts. Ford FR, in his classic textbook, Diseases of the Nervous System in Infancy, Childhood and Adolescence, 4th ed (Springfield Illinois, CC Thomas, 1960), refers to precocious puberty seen occasionally in cases of tuberous sclerosis and von Recklinghausen's disease. The association with optic pathway tumors and NF-1, emphasized in the present Chicago study, was noted in a 1979 article cited by the authors (Tertsch D et al. Pubertas praecox in neurofibromatosis of the optic chiasm. Acta Neurochir (Wien); 28(suppl):413).

\section{DEGENERATIVE - METABOLIC DISEASES}

\section{HARP SYNDROME}

Harp syndrome, characterized by hypoprebetalipoproteinemia, acanthocytosis, retinitis pigmentosa, and pallidal degeneration, is described in three patients from the National Hospital, Queen Square, London, Newcastle General Hospital, and the Royal Free Hospital, London, UK. An 18-year-old woman presented with intellectual subnormality, night blindness, and dysarthria and dysphagia associated with orobucco-lingual dystonia. T2weighted MRI showed the "eye-of-the-tiger" sign. This patient's sister and mother had hypoprebetalipoproteinemia but no retinitis pigmentosa or pallidal degeneration. Two patients with a forme-fruste Harp syndrome had the clinical and radiologic features but no lipid abnormality. (Orrell RW et al. Acanthocytosis, retinitis pigmentosa, and pallidal degeneration: A report of three patients, including the second reported case with hypoprebetalipoproteinemia (HARP syndrome). (Reprints: Dr Richard W Orrell, Academic Unit of Neuroscience, Charing Cross Hospital, Fulham Palace Rd, London W6 8RF, UK). 